This is the peer reviewed version of the following article: Holly, D, Swanson, V. Barriers and facilitators of midwives' physical activity behaviour in hospital and community contexts in Scotland. J Adv Nurs. 2019; 75: 2211- 2222, which has been published in final form at https://doi.org/10.1111/jan.14100. This article may be used for non-commercial purposes in accordance with Wiley Terms and Conditions for self-archiving.

DR DEIRDRE HOLLY (Orcid ID : 0000-0002-2426-5295)

DR VIVIEN SWANSON (Orcid ID : 0000-0002-1685-2991)

Article type : Original Research: Empirical research - mixed methods

\title{
Full Title: Barriers and Facilitators of midwives' physical activity behaviour in hospital and community contexts in Scotland.
}

Running Head: Midwives' physical activity behaviour

Authors: Deirdre HOLLY, DHealthPsych

1. Health Psychologist, NHS Education for Scotland, 2 Central Quay, Glasgow, G3 8BW

\section{Vivien SWANSON, PhD}

1. Reader in Health Psychology, Faculty of Natural Sciences, University of Stirling, Stirling FK9 4LA

2. Programme Director-Psychology Specialist Practice, NHS Education for Scotland, 2 Central Quay, Glasgow, G3 8BW

Contact details for corresponding author: Vivien.swanson@stir.ac.uk

ORCID ID: ps://orcid.org/0000-0002-1685-2991

\section{Acknowledgements}

This study was supported by NHS Education for Scotland. We are grateful to all of the midwives who took part.

No conflict of interest has been declared by the authors

This article has been accepted for publication and undergone full peer review (not applicable for Editorials) but has not been through the copyediting, typesetting, pagination and proofreading process, which may lead to differences between this version and the Version of Record. Please cite this article as doi: 10.1111/jan.14100 This article is protected by copyright. All rights reserved. 


\section{Authors' Contributions}

\begin{tabular}{|l|l|}
\hline Criteria & Author Initials \\
\hline $\begin{array}{l}\text { Made substantial contributions to conception and design, } \\
\text { or acquisition of data, or analysis and interpretation of } \\
\text { data; }\end{array}$ & DH \\
\hline $\begin{array}{l}\text { Involved in drafting the manuscript or revising it critically } \\
\text { for important intellectual content; }\end{array}$ & Drafting DH \\
\hline $\begin{array}{l}\text { Given final approval of the version to be published. Each } \\
\text { author should have participated sufficiently in the work to } \\
\text { take public responsibility for appropriate portions of the } \\
\text { content; }\end{array}$ & DH \\
\hline $\begin{array}{l}\text { Agreed to be accountable for all aspects of the work in } \\
\text { ensuring that questions related to the accuracy or integrity } \\
\text { of any part of the work are appropriately investigated and } \\
\text { resolved. }\end{array}$ & VS \\
\hline
\end{tabular}

\section{ABSTRACT}

Aims

To investigate barriers and facilitators of physical activity in midwives in hospital and community environments.

Design

A sequential mixed-methods approach.

Data Sources

Focus groups and subsequent questionnaire survey.

Methods

Four focus groups were conducted in urban and rural areas with community and hospitalbased midwives in Scotland in 2015. Topics were based on the behaviour change theories 
via the Theoretical Domains Framework. Findings informed development of a questionnaire, sent to midwives in 2016 in Scottish health boards via managers, or online survey.

Results

Thirty-three midwives participated in focus groups. Workplace environmental context and resources were both barriers and facilitators. Similarly, negative social influences were barriers, whereas positive social support facilitated physical activity.

The questionnaire was completed by 345 midwives. Most (90\%) were physically active with high levels of activity. Commonest activities included walking, swimming and housework. Physical activity facilitators included subsidized classes and protected breaks. Barriers included tiredness, stress, family responsibilities, unpredictable breaks and shift patterns.

\section{Conclusions}

Interventions should address midwives' workplace context and resources and interpersonal factors such as stress and social support.

Impact

Midwives' high levels of overweight/obesity and stress impact on their own health and delivery of patient care. More workplace physical activity could help. We found most were physically active but identified workplace barriers and facilitators, including resources, shift patterns and breaks. Findings could help midwifery managers to recognize and reduce barriers, thereby improving midwives' physical activity in the workplace, supporting weight management and enhancing their health and well-being.

\section{KEYWORDS}

midwives, physical activity, behaviour change, barriers and facilitators, healthcare environment, work patterns, social support 


\section{INTRODUCTION}

Physical activity (PA) and combating sedentary behaviour are key UK (Bull \& the Expert Working Groups, 2010) and international health priorities (World Health Organization, 2010). PA is associated with better physical and mental health including lower blood pressure (Booth, Roberts \& Laye, 2012; Warburton, Nicol \& Bredin, 2006), primary prevention of ischemic heart disease, diabetes and breast cancer (Kyu et al., 2016) and positive effects on mental health problems including stress and depression (Bernard et al., 2018; Penedo \& Dahn, 2005). Physical inactivity in women may result in a $52 \%$ increase in all-cause mortality (Hu et al., 2004). Even minor PA improvements are associated with reduced mortality (Warburton et al., 2006) and improved mental well-being, with a dose-response relationship (Bernard et al., 2018).

Background

Research identifying health behaviours of healthcare professionals (HP) in the UK is limited. Nursing is predominantly a female profession (The Health Foundation, 2016) and obesity is more prevalent among nurses (27\%), than the general population (25\%) (Bogossian et al., 2012). Up to 59\% of UK nurses may meet criteria for overweight/obesity (Bogossian et al., 2012; Hawker, 2012; Luszczynska \& Haynes, 2009; Malik, Blake \& Blatt, 2011), with over $30 \%$ of nurses and midwives aged 55-64 being obese in one study (Bogossian et al., 2012). This is concerning due to the relationship between obesity and health, including susceptibility to long-term conditions, impact on productivity and sick leave (Goettler, Grosse, \& Sonntag, 2017). Obesity is associated with poorer mental health, including stress, depression and anxiety (Gariepy, Nitka \& Schmitz, 2010; Luppino et al., 2010). Obesity can reduce HPs' credibility and confidence in health promoting efforts with patients (Leske, Strodl \& Hou, 2012; Puhl, Gold, Luedicke \& DePierre, 2013; Power, Kiezebrink, Allan \& Campbell, 2014; While, 2015).

This article is protected by copyright. All rights reserved. 
Although determinants of obesity are complex, two main influences are PA and diet (Glonti et al., 2016). UK-based research suggests nurses' PA does not meet recommended levels and is below World Health Organization recommendations of 150 minutes of moderate intensity activity per week (Luszczynska \& Haynes, 2009). Only 24\% of student nurses (Hawker, 2012) and 55\% of qualified nurses met UK Department of Health PA guidelines (Malik et al., 2011), compared with $71 \%$ of men and $58 \%$ of women in Scotland (The Scottish Government, 2013).

Health care workers' opportunities for PA occur in personal (e.g. leisure time activities, housework, family travel) and workplace contexts (e.g. travel to work, walking between sites as part of the job role; during lunch breaks). It is difficult to separate these and they can be interactive. This study focuses on workplace PA as being amenable to change by managers and policy makers to improve midwives' health and well-being, but also investigates more general barriers and facilitators of PA. Limited research has explored influences on nurses' workplace PA. Shift patterns may affect PA levels. Night shift workers are less likely to be active out of work or actively commute and rotating night shift workers may be more inactive than non-night shift workers especially among those reporting over eight night shifts a month (Peplonska, Bukowska \& Sobala, 2014). A recent survey (RCM; Royal College of Midwives, 2016) reported approximately 50\% of respondents' personal lives suffered due to work and $48 \%$ reported feeling stressed on all, or most days. Many respondents reported missing breaks (57\%) and working unpaid overtime (17\%). To date, no work has investigated factors influencing PA among midwives, comparing hospital and community-based employees, in Scotland or the UK. Community based midwives may have more autonomy and less predictability regarding day to day work planning and increased travel, particularly those working in remote and rural areas, than team-based hospital based midwives working in a single location. These factors could all potentially influence PA opportunities during the 
working day. Ongoing changes to a more person-centred, community based model of midwifery working in Scotland (Scottish Government, 2017) could also impact on midwives' PA opportunities.

It is important to understand factors influencing health behaviours such as PA when designing interventions to improve midwives' health and well-being. Behavioural theories, such as the Theory of Planned Behaviour (Ajzen \& Fishbein, 1980) emphasize the role of predictors including motivation and self-efficacy, or perceived behavioural control as determinants of intention and behaviour. Identifying barriers and facilitators can develop awareness of factors influencing motivation and control and is therefore a useful step in informing intervention development. Specific behaviour change techniques (BCTs) to address barriers and facilitators can be identified and targeted to maximize intervention efficacy. Informed by psychological theories of behaviour change, psychologists have developed detailed descriptions of BCTs and the competencies required to perform them (Abraham \& Michie, 2008), enabling techniques used in interventions to be described in a theoretically structured manner. This enhances intervention effectiveness and facilitates more accurate reporting, enhancing replicability (Taylor, Connor \& Lawton, 2012).

\section{THE STUDY}

\section{Aims}

Although behavioural theories provide helpful PA determinants, research has yet to identify which factors are most appropriate for midwives. This study aimed to investigate barriers and facilitators of PA in a midwifery population working in different urban and rural contexts in Scotland to inform future interventions to increase PA behaviour. We also aimed to investigate midwives' motivations and perceptions of PA and context-specific issues 
affecting midwives' uptake of PA during their working day (referred to as 'workplace PA'), including environmental factors and fit between job role, lifestyle and workplace PA.

Design

This was a sequential mixed-methods study in 2 stages. Study 1 included focus groups with hospital- and community-based midwives in rural and urban areas, exploring barriers and facilitators to PA to inform questionnaire content. Study 2 comprised a large-scale survey distributed to all 14 Scottish Health Board areas, which include areas of high urban concentration and remote and rural areas. Sampling from these different work contexts was considered useful to inform intervention development.

Studies were guided by the Theoretical Domains Framework (TDF), which synthesizes constructs from over 30 behaviour and behaviour change theories into a set of 13 broad domains, reflecting cognitive, emotional and social/environmental constructs, which can be mapped onto elements of the Behaviour Change Wheel (BCW), (Michie, Atkins \& West, 2014), a tool which can be used to develop interventions. The BCW describes broad factors, including within (e.g. providing education or incentives) and beyond individual control (e.g. policies or fiscal measures), which increase likelihood of engaging in target behaviours. Using the TDF (Michie, Johnston, Abraham, Lawton, Parker \& Walker, 2005), identifies specific intervention functions, which can be implemented and tailored to the target population using BCTs (Table 1).

The BCW and integrated TDF have been applied widely (Barker, Atkins, \& de Lusignan, 2016; Connell, McMahon, Redfern, Watkins \& Eng, 2015) to address multi-level factors influencing behaviour. The ability to simultaneously consider multiple contributing factors suggests a potential utility for the model, its underlying framework and application within the context of midwives' PA.

This article is protected by copyright. All rights reserved. 


\section{STUDY 1}

Participants

Four focus groups were carried out including midwives from two hospital and two community-based services, in urban and rural areas across central Scotland. These included 33 midwives, including 19 community and 14 hospital-based midwives (2 assistants were included as their job role mirrored that of qualified midwives). Group size varied from 4-12 people depending on who was available to participate. This mix of settings was targeted to identify setting-specific issues. Access to the services was negotiated by a senior midwifery colleague, who contacted Heads of Midwifery in services across Scotland. Willing volunteers were then sought from each service by Heads of Midwifery. To limit the burden associated with attendance, focus groups took place before or after team meetings.

\section{Data Collection}

Focus groups, carried out between June - September 2015, duration approximately 60 minutes, were led by a health psychologist (DH) assisted by an independent senior midwife, who clarified midwifery-specific issues. The senior midwife sought prior permission from the group to attend. The topic guide, developed collaboratively by psychologists and a senior midwife, was designed to identify barriers and facilitators of midwives' PA, based on TDF components (Michie et al., 2014). An introduction was included to contextualise the work, as follows: "Physical activity includes all forms of activity, such as everyday walking or cycling to get from A to B, active play, work-related activity, active recreation (such as working out in a gym), dancing, gardening or playing active games, as well as organised and competitive sport" and to ensure a shared understanding between the research team and the participants. 
Participants were informed that the focus groups would address both PA related to the workplace (including travel to work) and non-work (leisure time) PA.

Ethical considerations

The study protocol was reviewed by the organization's internal research governance committee and deemed to not require formal NHS ethical approval. To maintain confidentiality and anonymity we do not identify Health Board or individual demographic characteristics of participants in analyses.

\section{Data Analysis}

Focus groups were audio-recorded and transcribed verbatim. Deductive thematic analysis of data was carried out (Braun \& Clarke 2006). One researcher (DH) read and re-read transcripts to become familiar with the data, allocating specific statements to codes. Codes were grouped based on predetermined TDF themes (Michie et al., 2014). A note of TDF themes is in Table 1, Column 1.

\section{Rigour}

While the authors were keen to include as many participants as possible, they requested that no Heads of Midwifery/Service Leads attend focus groups, as they may have influenced free discussion of issues. Participation was voluntary and confidentiality was stressed. During data analysis, allocation of codes to themes were discussed and agreed with the co-author during regular meetings. Themes were subsequently discussed with an independent health psychologist with TDF experience to confirm that codes mapping was reliable and appropriate. 


\section{RESULTS}

Two overarching themes were identified, highlighting barriers and facilitators, namely environmental context and resources (e.g. shift working; subsidised facilities) and social support (e.g. being active, taking breaks with others). Within 'barriers', subordinate themes included 'emotion' (e.g. stress, fatigue) and intentions (lack of motivation).

\section{Environmental context and resources}

\section{Barriers to $P A$}

Environmental barriers related to those preventing active commuting to work and activity at work. The barriers to active commuting could broadly be categorised as relating to factors intrinsic to the job, such as shift patterns:

"After twelve and a half hour shifts there's no way..." [Urban Hospital]

Or the built environment around the hospital:

"...there's no cycling lanes... it's actually not safe... "[Rural Community].

Across both settings, the midwife role and working context (hospital or community setting) appeared to have a negative impact on their ability to be active, both at work and more generally. Shift length interfered with the ability to be active, especially among those with changeable shifts:

"I work long shifts, twelve and a half hour shifts, so there's not really ... your lunch break is half an hour. There's not time in the working day really to ... there's not time to exercise for me before work" [Urban Hospital]. 
Shift patterns had a detrimental impact on ability to be active, being outside midwives control. In particular, hospital-based groups mentioned that they were no longer allowed to mix day and night shifts or swap shifts, limiting their options to be active.

“...it's hard when you're working shifts” [Rural Hospital].

Participants stated they were more likely to be inactive on days off, as this time was used to recover:

"I would never think of doing that on my day off because you're recovering from your twelve-hour shift [Urban Hospital].

In addition, many of the midwives reported they were physically restricted by their job, which did not allow them the freedom to move about:

"All the time I'm sitting because even when l'm doing office work I'm sitting, when I'm doing my clinic work I sit talking, or I'm teaching then I'm standing so I'm not physically moving about at all" [Rural Hospital].

Lastly, inconsistency in terms of breaks, quite often due to staff shortages, had an impact on activity levels:

"I don't have tea breaks or anything, not that I go away from my desk but I sit and have my lunch" [Urban Community].

This article is protected by copyright. All rights reserved. 
Emotion

Barriers to $P A$

It was frequently reported that tiredness and stress from the day prevented midwives from being active during breaks:

"But it is as if everything's got worse. That's when people just sit in the coffee room and refuel" [Rural Hospital]

This effect was also seen during free time, even among those with access to leisure facilities:

"In some ways, the pressures of the day at work would influence me not to go to the gym, which it shouldn't do" [Urban Community].

Motivation to engage in PA

Some midwives appeared motivated to increase their PA but found this difficult in the context of their work routines.

\section{Barriers to $P A$}

Many of the midwives struggled to develop routines and habits that involved them being physically active. In addition to the tiredness and stress, lack of motivation also prevented them from being active:

"I finish at quarter to three, or at six if I'm doing a Friday, but I don't want to go to the gym. I have no notion ever." [Urban Hospital]

This also appeared to have an impact on free time that they had during their working day:

This article is protected by copyright. All rights reserved. 
"I used to enjoy just going across to the canteen and just either ... or getting fresh air outside. It was enjoyable getting out of the unit and exercising, but you just think, I can't be bothered" [Rural Hospital].

\section{Facilitators of $P A$}

Various potential enablers of PA were suggested during focus groups, including cheaper/subsidised access to leisure facilities:

"if it was cheaper, more a family thing... I could put mine(child) into the wee crèche thing

or something like that. Then I could go to the classes, not so much the gym but I can go to the classes for different things" [Urban Hospital].

Social influences

In terms of facilitators of general PA, those who were physically active quite often had other people that they could be active with, for instance:

"I'll go and walk with the neighbour if she wants to go for a walk..." [Urban Hospital].

Social support appeared to be an important influencer of PA, whether this was in terms of being active with others, or attending some form of structured class:

"I need to go somewhere where somebody's taking the class and making you do it" [Urban Hospital]

Many of the midwives who were active spoke of walking with others, including family and friends:

This article is protected by copyright. All rights reserved. 
"I think when you've got children it's a big motivation" [Urban Community].

Social support was also important for PA in the workplace. Where people could take breaks together, this had a positive impact:

“...it depends if there's anybody else wanting to do it. If you're on your own it's not so inviting, but if somebody else wants to go, it's fab" [Rural Community].

Similarly, some people had participated in workplace PA challenges and found these beneficial:

"you become competitive against the others, obviously and yourself; you want to get to your ten thousand steps at the end of the day" [Rural Community].

As well as workplace challenges, both hospital and community-based midwives stated they thought classes in the workplace, such as tai chi or relaxation could help them be more active.

\section{STUDY 1: DISCUSSION}

Focus groups carried out with hospital and community-based midwives in urban and rural settings identified barriers and facilitators to PA both in the workplace and more generally. The most important factors were environmental context and resources (e.g. long shifts, unpredictable breaks) and social support (e.g. having others that they could be active with). Findings from the focus group were subsequently used to develop a questionnaire to explore the impact of these factors on PA in a larger sample of midwives in Study 2.

This article is protected by copyright. All rights reserved. 


\section{STUDY 2}

\section{Participants}

Eligible participants were hospital or community-based midwives employed in Scotland. There were 2,352 qualified midwifery staff in post in Scotland in 2015/6 (Information and Statistics Division, 2017). We aimed to recruit sufficient participants across Scotland to compare PA barriers and facilitators, recognising the over-representation of hospital-based midwives in health services, to inform intervention development. There were no specific inclusion/exclusion criteria.

Data Collection

The brief exploratory 14 item questionnaire was developed by the study team and senior midwifery colleagues and reviewed for face validity by senior midwives in 2 health boards. It evaluated age group (scored 1-6) rather than actual age, (to preserve confidentiality), base, work hours, travel to work method, physical activity types, minutes per week and steps and barriers and facilitators to PA in general and in the workplace. Using themes from Study 1, it aimed to assess content and reliability of factors identified in focus groups in a larger, representative sample. It was kept deliberately brief to encourage completion. The questionnaire featured four TDF components identified in focus groups: Environmental context and resources (questions 6,8,12,14); social influences (questions 8,12) emotion (question 13) and motivation (intentions) (question 5,13). Using the TDF components and issues raised in the focus groups, participants responded to a series of questions. Table 2 includes questions and response options.

Participants were required to indicate binary ('yes'; score 1), ('no'; score 0) responses to items in the questionnaire. Where appropriate, free-text responses were required, e.g. typical number of minutes being active per week. Types of PA included in the questionnaire were 
taken from the population-based Scottish Health Survey (The Scottish Government, 2013). We focused on perceived barriers and facilitators of PA engagement, rather than rigorous assessment of intensity and duration. This may have compromised the reliability of PA data (Sylvia, Bernstein, Hubbard, Keating \& Anderson, 2015), but was used to improve questionnaire engagement in this group of health professionals.

The questionnaire was distributed from January to March 2016, using 'QuestBack', an online survey management system. The link was e-mailed to Heads of Midwifery within each of 14 territorial Health Boards in Scotland. To overcome the issue of lack of access to a workplace computer, paper questionnaires were also distributed accompanied by stamped addressed envelopes, by midwifery contacts in the Health Boards, identified by Senior Midwives. Contacts were sent an envelope containing questionnaires, allocated based on the number of midwives employed as follows: smaller health boards $(5 \mathrm{x}<100$ midwives) received 10; medium size boards ( 4 x 100-249 midwives) received 30; large ( 5 x >250 midwives) received 60 (total 470). In both cases, the Heads of Midwifery were asked to cascade the questionnaire to their staff across the board, invite them to complete and return it to the authors. They could request further copies if needed.

Ethical Considerations

This study was reviewed by the organisation's Research Governance Committee and deemed to not require NHS Ethical Approval. Return of the completed questionnaires was considered consent to participate. To preserve anonymity we did not collect information on participants' health board (since some boards have very small numbers of midwives).

Analysis

The completed responses from the questionnaires were entered into SPSS Version 22 and analysed using descriptive analysis. Anova was used to compare group means and chi square 
tests applied to categorical data. Respondents from 'Community', 'Hospital' and 'Mixed' workplaces (i.e. working in both community and hospital contexts) were initially compared in terms of hours worked per week using one-way Anova. The 'mixed' group was much smaller $(n=22)$. There were significant differences in hours worked per week (see below) but post hoc (LSD ) comparisons showed that these differences lay between hospital and the other 2 groups. The community and mixed groups were therefore combined for chi square analyses. A threshold significance level of $p=.05$ was adopted throughout.

\section{Validity and Reliability}

The questionnaire was exploratory, developed from focus groups including participants from the groups of professionals (midwives) under study and reviewed by experts before use. The TDF has shown good content and face validity in previous research, is based on theory synthesis and expert review and has been validated for use in behavioural research (Cane, O’Connor \& Michie, 2012).

\section{RESULTS}

The questionnaire was completed by 345 midwives, 209 (44\%) paper-based and 136 via QuestBack. Of these, 256.74\% were hospital-based, 67,19\% community-based and $22.6 \%$ 'mixed' hospital and community based. Response rate for paper questionnaires was $44 \%$ (209/470), it was not possible to calculate this for the QuestBack responses. Participants were relatively experienced, with most $(119,35 \%)$ aged $45-54$ and $93.27 \%$ aged 55-64, (representing an overall mean age group of 3.7, SD 1.2). Community midwives were older (mean age group 4.0, SD 1.1) than hospital (mean 3.6, SD 1.2) and mixed groups (mean 3.6, SD 1.1); $(\mathrm{F}(2,342)=3.6, \mathrm{p}=.03)$. Mean number of hours worked by respondents was 33.4, SD 
6.8, (range 15-55). Community (mean 34.7, SD 5.1) and mixed (mean 36.1, SD 4.9) groups worked longer hours than hospital midwives (mean 32.8, SD 7.2); $(\mathrm{F}(2,342)=3.68, \mathrm{p}=.03)$.

\section{Current PA}

Most $(312,90 \%)$ participants stated they were currently physically active. Mean estimated time engaged in PA per week was 303.2 minutes (SD ,212.3) (range 5-1680). There was no group difference in reported activity time; (community mean 310.4, SD 274.8); (hospital mean 298.8, SD 194.8); Mixed (mean 336.4, SD 206.1); $(\mathrm{F}(2,276)=.27, \mathrm{p}=.76)$. The most common facilitators of PA were 'enjoying being active with my family' (179, 54\%), 'having a dog that needs to be walked' $(125,39 \%)$ or 'having active friends' $(69,21 \%)$. There were no group differences in facilitators.

The types of PA undertaken are shown in Table 3. The pattern was similar for all groups. A small number of participants $(\mathrm{n}=29,8 \%)$ undertook other activities including home exercise DVDs, dancing, horse riding and golf.

\section{INSERT TABLE 3 HERE}

Mean steps per day reported by those using an activity monitor $(95,28 \%)$ was 10,777 , SD ,39544.5; (range, 600-25,000). There was no significant difference between community (mean 11,636, SD , 4001), hospital (mean 10,789, SD ,4038) and 'mixed' midwives (mean $9,286, \mathrm{SD}, 2797)$ in terms of the number of steps per day $(\mathrm{F}(2,92)=.75, \mathrm{p}=.47)$.

\section{Environmental Context and Resources}

Most participants $(304,88 \%)$ drove to work, only $32,9 \%$ actively commuted. Of the remainder, 242, 70\% had never considered an active commute. Most frequently rated barriers to active commuting (Table 2, Question 6) included distance to work, (176,53\%), lack of fit with working long hours $(79.24 \%)$, covering a large area $(58.18 \%)$, unsafe roads $(46.14 \%)$, needing to carry equipment (43.13\%) and enjoying driving (18.6\%). 
Chi-square tests compared identified barriers to active commuting for community (and mixed) and hospital-based midwives. Hospital based midwives were more likely than others to state that long hours $\left(68,28 \%\right.$; vs. $\left.11,13 \% ; \chi^{2}(\mathrm{df} 1)=8.23, \mathrm{p}=.002\right)$ discouraged active commuting. For community-based midwives, (compared with hospital-based) covering a large area $\left(45,52 \%\right.$; vs. $\left.13,5 \% ; \chi^{2}(\mathrm{df} 1)=95.1, \mathrm{p}<.001\right)$ and the need to carry equipment $\left(35,40 \%\right.$; vs. $\left.8,3 \% ; \chi^{2}(\mathrm{df} 1)=77.1, \mathrm{p}<.001\right)$ were more likely to prevent active commuting.

\section{Barriers to PA}

General and job-specific barriers to PA are shown in Table 4a. The most common general factors included tiredness/fatigue and family responsibilities. Emotional factors including stress and low motivation were also important. There were no differences in general PA barriers for hospital or community midwives.

The most common job-specific barriers shown in Table 4 were unpredictable breaks, shift patterns and long shifts and the sedentary nature of work. Hospital-based midwives were more likely to report shift patterns $\left(\chi^{2}(\mathrm{df} 1)=9.4, \mathrm{p}=.002\right)$ and long shifts $\left(\chi^{2}(\mathrm{df} 1)=3.8, \mathrm{p}=.05\right)$ as a barrier, whereas more community midwives reported eating lunch at their desk as a $\operatorname{barrier}\left(\chi^{2}(\mathrm{df} 1)=7.9, \mathrm{p}=.007\right)$.

Facilitators of PA

Facilitators of PA were identified by $198.57 \%$ currently inactive midwives (Table 4b). The most common were having subsidised or cheaper access to facilities, protected breaks, exercise classes at work and organised workplace PA challenges. There were few group differences. Community-based staff were more likely to say that work-based exercise classes would help them be more active $\left(\chi^{2}(\mathrm{df} 1)=8.0, \mathrm{p}=.005\right)$. 


\section{STUDY 2: DISCUSSION}

A cross-sectional survey examined barriers and facilitators to PA in general and at work, for midwives across Scotland. Participants were a more active group than anticipated, however, several barriers including environmental context and resources and negative emotions were suggested to impede PA. Importantly many of the work-related barriers identified were organizational rather than individual. These included long hours, shift patterns and a workplace environment not conducive to PA.

Activity levels

Most (90\%) respondents considered themselves to be physically active, with substantially more activity than the current recommended 150 minutes (of moderate intensity) per week (UK Department of Health, 2011). Similarly, those who reported step counts using activity monitors reported mean values over 10,000 steps per day. However our data were self-report and we did not record PA intensity, so this data should be treated with caution. Reported PA did not differ significantly between settings, despite typically differing work patterns. These PA figures are higher than those reported elsewhere (Hawker, 2012; Malik et al., 2011) and higher than the Scottish Health Survey for specific forms of PA (The Scottish Government, 2013). The most popular involved 'informal' activity such as walking, swimming and housework/DIY/gardening, which are easily available and less restricted by schedules related to shift patterns.

Barriers and facilitators of PA

Many women experience difficulties fitting PA into their schedule (Scottish Health Survey, 2013), but it may be more difficult for hospital-based midwives. Organisational level barriers related to unpredictable breaks and sedentary work patterns, which affected all midwives and shift patterns and working long shifts, which were more common barriers for hospital-based 
staff. A recent RCM survey (The Royal College of Midwives, 2016) noted similar findings, such that their participants often worked more than their contracted hours. This also mentioned the inability to take breaks, or shortened breaks due to staffing issues or emergencies. These demanding work patterns may be related to increased obesity (Han, Trinkoff, Storr, Geiger-Brown, Johnson \& Park, 2012), having a long-term detrimental impact on midwives' health. Conversely, the ability to adapt to shift work may be helped by using PA to cope with stress, by lowering levels of fatigue and sleepiness (Saksvik, Bjorvatn, Hetland, Sandal \& Pallesen, 2011).

PA facilitators identified in the survey include cheaper and more readily available facilities, including workplace-based classes (endorsed by more community midwives). Social influences on PA, including workplace challenges, family-based activity and breaks with colleagues were also important. Emotional factors including stress and tiredness/fatigue sometimes prevented PA. This is expected since many midwives worked long hours and commuted a long distance to work, as noted elsewhere (Royal College of Midwives, 2016). Encouraging 'light' and available forms of PA (such as walking) during the working day may be worthwhile, along with more general acknowledgement of the need to improve health and well-being in this population (Perry, Nicholls, Diffield \& Gallagher, 2017).

\section{CONCLUSIONS}

Our studies make specific recommendations for managers and policy makers regarding barriers and facilitators to PA in midwives in Scotland. The qualitative study provided clear pointers, using TDF constructs, to inform interventions to promote PA, improving physical health and mental well-being. This facilitates mapping of intervention components (Michie et al., 2014) by identifying specific behaviour change techniques (Table 1). We identified components, including environmental context and resources, social influences, motivation (intention) and emotions which could be addressed in a workplace intervention to improve 
midwives PA. A recent Delphi study suggested interventions should include staff education, communication and electronic prompts to remind midwives of exercise goals (Perry et al., 2017), however focusing on individual staff behaviours may be insufficient without attention to organizational, environmental, social and emotional factors.

Social support is important for PA engagement, here and elsewhere (Greaney, Puleo, Sprunck-Harrild, Haines, Houghton \& Emmons, 2018; Wen et al., 2005). Workplace interventions could increase midwives' general self-efficacy and self-regulation via support (Rackow, Scholz \& Hornung, 2015). Team-based interventions (DeCocker, De Bourdeaudhuij, \& Cardon, 2009; Freak-Poli, Wolfe, Backholer, De Courten, \& Peeters, 2011) may be useful.

\section{Limitations}

Several biases are possible. It may be that midwives who were more active or more motivated to change PA behaviour participated. We did not collect socio-demographic information regarding midwives' geographical health board, client base/location (including socio-demographic data) or detailed role characteristics. Similarly we did not collect details of participants' weight status. This could have provided important information about PA, would have been helpful in interpreting our data and also may have been a source of respondent bias. Additionally, response rates for the paper-survey were relatively low and we were unable to determine response rates for online-data collection, so may have overrepresented participants with more interest and engagement in PA. Participants were not asked about PA intensity, which has implications for associated health benefits. Walking, housework, gardening and DIY were PA options which may have very variable intensity. Accurate measurement of PA is complex and we acknowledge the pragmatic, self-report method we adopted (due to time and resource constraints) may not have been reliable (Sylvia et al., 2015). Our division of midwives into 'hospital' and 'community' may not have 
sufficiently reflected the scope and breadth of different workplace roles, particularly in a country like Scotland where there is substantial geographical variation in size and degree of specialization of units, accessibility and travel distances between remote and rural and urban/suburban settings.

Nevertheless our studies are very timely. Currently Scotland's 'Best Start' programme (Scottish Government, 2017) is developing new care pathways for recipients of midwifery services, which aim to deliver a more individually tailored, community driven service. This will also deliver challenges to midwives' existing ways of working and may have positive or negative implications for their health and well-being. Supporting interventions which aim to ensure optimal physical activity involvement for midwives, within and outside their working day, can only be beneficial in this context. Supporting a healthier, less stressed midwifery workforce will lead to improved morale, less sickness absence and improved job performance, with positive benefits for midwifery care.

This article is protected by copyright. All rights reserved. 


\section{REFERENCES}

Abraham, C., \& Michie, S. (2008). A taxonomy of behaviour change techniques used in interventions. Health Psychology, 27(3), 379-387. doi: 10.1037/0278-6133.27.3.379.

Ajzen, I., \& Fishbein, M. (1980). Understanding attitudes and predicting social behaviour. Engle-Wood Cliffs, NJ: Prentice Hall.

Barker, F., Atkins, L., \& de Lusignan, S. (2016). Applying the COM-B behaviour model and behaviour change wheel to develop an intervention to improve hearing-aid use in adult auditory rehabilitation. International Journal of Audiology, 1-9. doi: $10.3109 / 14992027.2015 .1120894$

Bernard, P., Dore, I., Ahmed-Jérôme, R., Hains-Monfette, G., Kingsbury, C., \& Sabiston, C. (2018). Dose response association of objective physical activity with mental health in a representative national sample of adults: A cross-sectional study. PLoS One, 13(10) doi: http://dx.doi.org/10.1371/journal.pone.0204682

Bogossian, F.E., Hepworth, J., Leong, G.M., Flaws, D.F., Gibbons, K.S., Benefer, C.A., Turner, C.T. (2012). A cross-sectional analysis of patterns of obesity in a cohort of working nurses and midwives in Australia, New Zealand and the United Kingdom. International Journal of Nursing Studies, 6, 49(6), 727-738. doi: 10.1016/j.ijnurstu. 2012.01.003.

Booth, F.W., Roberts, C.K., \& Laye, M.J. (2012). Lack of exercise is a major cause of chronic diseases. Comparative Physiology, 2(2), 1143-1211. doi: 10.1002/cphy.c110025

Braun, V. \& Clarke, V. (2006). Using thematic analysis in psychology. Qualitative Research in Psychology, 3, 77-101. Doi:10.1191/1478088706qp063oa.

This article is protected by copyright. All rights reserved. 
Bull, F.C., \& the Expert Working Groups. (2010). Physical Activity Guidelines in the U.K.: Review and Recommendations. School of Sport, Exercise and Health Sciences: Loughborough University.

Cane, J., O’Connor, D., \& Michie, S. (2012) Validation of the theoretical domains framework for use in behaviour change and implementation research. Implementation Science, 7, 37. doi: $10.1186 / 1748-5908-7-37$

Chan, C.W. \& Perry, L. (2012). Lifestyle health promotion interventions for the nursing workforce: a systematic review. Journal of Clinical Nursing, 21(15-16), 2247-2261. doi: 10.1111/j.1365-2702.2012.04213.x.

Connell, L.A., McMahon, N.E., Redfern, J., Watkins, C.L., \& Eng, J.J. (2015). Development of a behaviour change intervention to increase upper limb exercise in stroke rehabilitation. Implementation Science, 10(1), 1. doi: 10.1186/ s13012-015-0223-3

De Cocker, K.A., De Bourdeaudhuij, I.M., \& Cardon, G.M. (2009). The effect of a multistrategy workplace physical activity intervention promoting pedometer use and step count increase. Health Education Research, 25(4), 608-19. doi: 10.1093/her/cyp052

Freak-Poli, R., Wolfe, R., Backholer, K., De Courten, M., \& Peeters, A. (2011). Impact of a pedometer-based workplace health program on cardiovascular and diabetes risk profile. Preventive Medicine, 53(3), 162-171. doi: 10.1016/j.ypmed.2011.06.005.

Gariepy, G., Nitka, D., \& Schmitz, N. (2010) The association between obesity and anxiety disorders in the population: A systematic review and meta-analysis. International Journal of Obesity, 34, 207-219. doi: 0307-0565/10

Glonti, K., Mackenbach, J.D., Ng J., Lakerveld, J., Oppert, J.M., Bárdos, H., McKee, M., \& Rutter, $\mathrm{H}$. 
(2016). Psychosocial environment: definitions, measures and associations with weight status- a systematic review. Obesity Review, 17(1), 81-95. doi: 10.1111/obr.12383.

Goettler, A., Grosse, A., \& Sonntag, D. (2017) Productivity loss due to overweight and obesity: A

systematic review of indirect costs. BMJ Open , 7:e014632. doi:10.1136/ bmjopen2016-014632

Greaney, M.L., Puleo, E., Sprunck-Harrild, K., Haines, J., Houghton, S.C. \& Emmons, K.M. (2018). Social support for changing multiple behaviours: Factors associated with seeking support and the impact of offered support. Health Education \& Behaviour. 45(2):198-206. doi: 10.1177/1090198117712333

Han, K., Trinkoff, A.M., Storr, C.L., Geiger-Brown, J., Johnson, K.L., Park, S. (2012). Comparison of job stress and obesity in nurses with favorable and unfavorable work schedules. Journal of Occupational and Environmental Medicine, 54(8), 928-32. doi: 10.1097/JOM.0b013e31825b1bfc.

Hawker, C.L. (2012) Physical activity and mental well-being in student nurses. Nurse Education Today, 32(3), 325-331. doi: 10.1016/j.nedt.2011.07.013.

Hu, F.B., Willett, W.C., Li, T., Stampfer, M.J., Colditz, G.A., \& Manson, J.E. (2004). Adiposity as compared with physical activity in predicting mortality among women. New England Journal of Medicine,351(26), 2694-2703. doi: 10.1056/ NEJMoa042135

Information and Statistics Division Scotland (ISD ) (2017). NHS Scotland Workforce information. Statistics: Retrieved from the Internet June 2018.

This article is protected by copyright. All rights reserved. 
https://www.isdscotland.org/Health-Topics/Workforce/Publications/2017-1205/2017-12-05-Workforce-Report.pdf\#page=19

Kyu, H.H., Bachman, V.F., Alexander, L.T., Mumford, J.E., Afshin, A., Estep, K... Forouzanfar M.H. (2016). Physical activity and risk of breast cancer, colon cancer, diabetes, ischemic heart disease and ischemic stroke events: systematic review and dose-response meta-analysis for the Global Burden of Disease Study 2013. British Medical Journal, 354, i3857. doi: https:// doi.org/10.1136/bmj.i3857

Leske, S., Strodl, E., \& Hou, X.Y. (2012). Patient-practitioner relationships desired by overweight/ obese adults. Patient education and Counseling, 89(2), 309-315. doi: 10.1016/j.pec.2012.07.002

Luppino, F.S., de Wit, L.M., Bouvy, P.F., Stijnen, T., Cuijpers, P., Penninx, B.W., Zitman, F.G. (2010).

Overweight, obesity and depression: A systematic review and meta-analysis of longitudinal

studies. Archives of General Psychiatry, 67(3), 220-229.

Luszczynska, A. \& Haynes, C. (2009). Changing nutrition, physical activity and body weight among student nurses and midwives. Effects of a planning Intervention and selfefficacy beliefs. Journal of Health Psychology, 14(8), 1075-1084. doi: 10.1177/1359105309342290.

Malik, S., Blake, H., \& Batt, M. (2011). How healthy are our nurses? New and registered nurses compared. British Journal of Nursing, 20(8), 489-496. doi: 10.12968/bjon.2011.20.8.489

This article is protected by copyright. All rights reserved. 
Michie, S., Johnston, M., Abraham, C., Lawton, R., Parker, D., \& Walker, A. "Psychological Theory" Group. (2005) Making psychological theory useful for implementing evidence based practice: a consensus approach. Quality \& Safety in Health Care, 14(1), 26-33. doi: 10.1136/qshc.2004.011155

Michie, S.F., Atkins, L., \& West, R. (2014). The Behaviour Change Wheel: A Guide to Designing Interventions. United Kingdom: Silverback Publishing.

Penedo, F.J., \& Dahn, J.R. (2005). Exercise and well-being: A review of mental and physical health benefits associated with physical activity. Current Opinion in Psychiatry, 18(2), 189-193.

Peplonska, B., Bukowska, A., \& Sobala, W. (2014). Rotating night shift work and physical activity of nurses and midwives in the cross-sectional study in Lodz, Poland. Chronobiology International, 31(10), 1152-1159. doi: $10.3109 / 07420528.2014 .957296$

Perry, L., Nicholls, R., Duffield, C., \& Gallagher, R. (2017). Building expert agreement on the importance and feasibility of workplace health promotion interventions for nurses and midwives: A modified Delphi consultation. Journal of Advanced Nursing 73,(11), 2587-2599. doi: 10.1111/jan.13345.

Power, B.T., Kiezebrink, K., Allan, J.L., \& Campbell, MK. (2014). Effects of workplacebased dietary and/or physical activity interventions for weight management targeting healthcare professionals: a systematic review of randomized controlled trials. BMC Obesity, 14(1), 23. doi: 10.1186/s40608-014-0023-3.

Puhl, R.M., Gold, J.A., Luedicke, J., \& DePierre, J.A. (2013). The effect of physicians' body weight on patient attitudes: implications for physician selection, trust and adherence

This article is protected by copyright. All rights reserved. 
to medical advice. International Journal of Obesity, 37(11), 1415-1421. doi: 10.1038/ijo.2013.33.

Rackow, P., Scholz, U., \& Hornung, R. (2015). Received social support and exercising: An intervention study to test the enabling hypothesis. British Journal of Health Psychology, 20(4), 763-76. doi: 10.1111/bjhp.12139

Saksvik, I.B., Bjorvatn, B., Hetland, H., Sandal, G.M., \& Pallesen, S. (2011). Individual differences in tolerance to shift work - A systematic review. Sleep Medicine Reviews, 15(4), 221-235. doi:10.1016/j.smrv.2010.07.002

Scottish Government, 2017. The Best Start, A Five-Year Forward Plan for Maternity and Neonatal

Care in Scotland. Crown Publications, Scotland. ISBN: 978-1-78652-764-6

Sylvia, L.T., Bernstein, E.E., Hubbard, J,L., Keating, L., \& Anderson, A. (2015) A practical guide to measuring physical activity. Journal of Academy of Nutrition and Diet, 114(2), 199-208. doi:10.1016/j.jand.2013.09.018.

Taylor, N., Connor, M., \& Lawton, R. (2012). The impact of theory on the effectiveness of worksite physical activity interventions: a meta-analysis and meta-regression. Health Psychology Review, 6(1): 33-73. doi: 10.1080/17437199.2010.533441

The Health Foundation. (2016). Staffing matters; funding counts - Supplement: Workforce profile and trends-The workforce of the NHS in England: current profile and recent trends

The Royal College of Midwives. (2016 ). Caring for You Campaign: Survey Results.

The Scottish Government, (2013). Scottish Health Survey.

UK Department of Health and Social Care, Physical Activity Guidelines, 2011.

This article is protected by copyright. All rights reserved. 
https://www.gov.uk/government/publications/uk-physical-activity-guidelines

Warburton, D.E., Nicol, C.W., \& Bredin, S.S. (2006). Health benefits of physical activity: The evidence. Canadian Medical Association Journal, 174, 801-809. doi: 10.1503/cmaj.051351

Wen, L.E., Orr, N., Bindon, J., \& Rissel, C. (2005). Promoting active transport in a workplace setting: evaluation of a pilot study in Australia. Health Promotion International, 20(2), 123-133. doi:10.1093/heapro/dah602

While, A. E. (2015). Promoting healthy behaviours - do we need to practice what we preach? London Journal of Primary Care,7(6), 112-114. doi: $10.1080 / 17571472.2015 .1113716$

World Health Organization. (2010). Global Recommendations on Physical Activity for Health.

This article is protected by copyright. All rights reserved. 
Table 1. Components of the Theoretical Domains Framework with Potential Intervention Functions and Behaviour Change Techniques

\begin{tabular}{|c|c|c|}
\hline Theoretical Domains Framework Component & Potential Intervention Functions & Potential Behaviour Change Techniques \\
\hline $\begin{array}{l}\text { Skills } \\
\text { Knowledge } \\
\text { Memory, attention \& decision process } \\
\text { Behavioural regulation }\end{array}$ & $\begin{array}{l}\text { Skills development } \\
\text { Develop specific plans to change }\end{array}$ & $\begin{array}{l}\text { Goal setting*, } \\
\text { Problem-solving, } \\
\text { Action planning, } \\
\text { Self-monitoring*, } \\
\text { Feedback*, }\end{array}$ \\
\hline $\begin{array}{l}\text { Social influences } \\
\text { Environmental context \& resources }\end{array}$ & $\begin{array}{l}\text { Elicit social support, } \\
\text { Avoid cues for behaviour } \\
\text { Change routines \& environment }\end{array}$ & $\begin{array}{l}\text { Social support (practical/emotional) } \\
\text { Restructuring the social/physical environment } \\
\text { Prompts and cues }\end{array}$ \\
\hline $\begin{array}{l}\text { Beliefs about capabilities } \\
\text { Beliefs about consequences } \\
\text { Social/Professional role \& identity } \\
\text { Motivation \& goals } \\
\text { Emotion }\end{array}$ & $\begin{array}{l}\text { Reward change } \\
\text { Develop appropriate beliefs } \\
\text { Develop positive feelings about change } \\
\text { Develop new habits }\end{array}$ & $\begin{array}{l}\text { Information about others' approval } \\
\text { Focus on past success } \\
\text { Verbal persuasion about capability }\end{array}$ \\
\hline
\end{tabular}

*can relate to both the target behaviour and the outcome of a target behaviour

This article is protected by copyright. All rights reserved. 
Table 2. Midwives Physical Activity Questionnaire and Response Options

\begin{tabular}{|c|c|}
\hline Question & Response options \\
\hline 1.Your age group & 1. 18-24; 2. 25-34; 3. 35-44; 4. 45-54; 5. 55-64; . 65 and over \\
\hline 2.Are you based in: & Hospital / Community \\
\hline $\begin{array}{l}\text { 3.How many hours do } \\
\text { you work in a typical } \\
\text { week? }\end{array}$ & Open-ended response \\
\hline $\begin{array}{l}\text { 4.How do you usually } \\
\text { travel to work? }\end{array}$ & $\begin{array}{llll}\text { Drive; } & \text { Bus/train/tram; Walk; } \quad \text { Cycle; Other (please specify) }\end{array}$ \\
\hline $\begin{array}{l}\text { 5. Have you ever } \\
\text { considered an active } \\
\text { commute (e.g. cycling or } \\
\text { walking) to work? }\end{array}$ & $\begin{array}{l}\text { Yes / No / } \\
\text { Already actively commute to work }\end{array}$ \\
\hline $\begin{array}{l}\text { 6.BARRIERS } \\
\text { What prevents you from } \\
\text { having an active } \\
\text { commute? }\end{array}$ & $\begin{array}{ll}\text { a. } & \text { I like driving to work } \\
\text { b. } & \text { I need to carry too much equipment } \\
\text { c. } & \text { I cover a large geographical area } \\
\text { d. } & \text { It doesn't fit with the long hours that I work } \\
\text { e. } & \text { I work too far away from home } \\
\text { f. } & \text { Unsafe roads }\end{array}$ \\
\hline $\begin{array}{l}\text { 7.Are you currently } \\
\text { physically active? }\end{array}$ & Yes / No \\
\hline $\begin{array}{l}\text { 8.FACILITATORS } \\
\text { If you are active, what } \\
\text { helps you be active? }\end{array}$ & $\begin{array}{ll}\text { a. } & \text { I like being active with my family } \\
\text { b. } & \text { My dog needs to be walked } \\
\text { c. } & \text { My friends are active } \\
\text { d. } & \text { My colleagues are active }\end{array}$ \\
\hline $\begin{array}{l}\text { 9.What types of physical } \\
\text { activity do you do? }\end{array}$ & $\begin{array}{ll}\text { a. } & \text { Walking } \\
\text { b. } & \text { Swimming } \\
\text { c. } & \text { Jogging/running } \\
\text { d. } & \text { Cycling } \\
\text { e. } & \text { Tennis/squash } \\
\text { f. } & \text { Badminton } \\
\text { g. } & \text { Basketball/netball/volleyball } \\
\text { h. } & \text { Football } \\
\text { i. } & \text { Bowls } \\
\text { j. } & \text { Yoga } \\
\text { k. } & \text { Gym workout/exercise bike/weights } \\
\text { l. } & \text { Housework } \\
\text { m. } & \text { Exercise class } \\
\end{array}$ \\
\hline 10.Approximately how & Open-ended response \\
\hline
\end{tabular}

This article is protected by copyright. All rights reserved. 


\begin{tabular}{|c|c|}
\hline $\begin{array}{l}\text { many minutes a week do } \\
\text { you spend doing the } \\
\text { activities you selected } \\
\text { above? }\end{array}$ & \\
\hline $\begin{array}{l}\text { 11.If you use a } \\
\text { pedometer/FitBit or } \\
\text { other form of activity } \\
\text { tracker, how many steps } \\
\text { do you do, in a typical } \\
\text { day? }\end{array}$ & Open-ended response \\
\hline $\begin{array}{l}\text { 12.FACILITATORS } \\
\text { If you aren't active, but } \\
\text { would like to be, what } \\
\text { would help? }\end{array}$ & $\begin{array}{l}\text { a. Having breaks with a colleague } \\
\text { b. Having protected breaks/meal times } \\
\text { c. Having facilities for showering/ changing at work } \\
\text { d. } \quad \text { Cheaper/subsidised access } \\
\text { e. } \quad \text { Structured exercise classes at work } \\
\text { f. Knowing what is available locally (both in the Trust and the } \\
\text { community) } \\
\text { g. Workplace physical activity challenges (e.g. a pedometer } \\
\text { challenge) } \\
\text { h. Activities that would include my family }\end{array}$ \\
\hline $\begin{array}{l}\text { 13.BARRIERS } \\
\text { What prevents you from } \\
\text { being more active, in } \\
\text { general? }\end{array}$ & $\begin{array}{ll}\text { a. } & \text { Tiredness/fatigue } \\
\text { b. } & \text { Childcare/other family responsibilities } \\
\text { c. } & \text { Lack of motivation } \\
\text { d. } & \text { Stress } \\
\text { e. } & \text { I'm not in the habit of being active }\end{array}$ \\
\hline $\begin{array}{l}\text { 14.BARRIERS } \\
\text { What prevents you from } \\
\text { being more active, at } \\
\text { work? }\end{array}$ & $\begin{array}{ll}\text { a. } & \text { Unpredictable breaks (e.g. emergencies, short staffing) } \\
\text { b. } & \text { Long shifts } \\
\text { c. } & \text { Shift patterns } \\
\text { d. } & \text { My job requires me to sit } \\
\text { e. } & \text { Tasks that mean I have to stay in the same place for a long } \\
\text { period of time. } & \\
\text { f. } & \text { I always eat lunch at my desk }\end{array}$ \\
\hline
\end{tabular}

${ }^{1}$ All fixed response questions included 'Other ..... (please specify...) response

This article is protected by copyright. All rights reserved. 
Table 3. Types of Physical Activity Undertaken by Hospital and Community Midwives

\begin{tabular}{|l|l|l|}
\hline Type & $\begin{array}{l}\text { Hospital-based } \\
\mathbf{N}=250\end{array}$ & $\begin{array}{l}\text { Community-based } \\
\text { and 'mixed' } \\
\mathbf{N}=89\end{array}$ \\
\hline Walking & $223(89 \%)$ & $73(87 \%)$ \\
\hline Housework/DIY/Gardening & $144(58 \%)$ & $46(55 \%)$ \\
\hline Swimming & $84(33 \%)$ & $26(31 \%)$ \\
\hline Gym workout/exercise bike/weight training & $77(31 \%)$ & $21(25 \%)$ \\
\hline Jogging/Running & $56(22 \%)$ & $19(23 \%)$ \\
\hline Cycling & $48(19 \%)$ & $17(20 \%)$ \\
\hline Yoga/Pilates/Tai Chi & $28(11 \%)$ & $19(23 \%)$ \\
\hline Badminton & $7(3 \%)$ & $1(2 \%)$ \\
\hline Tennis/Squash & $2(1 \%)$ & $3(4 \%)$ \\
\hline Football/Rugby & $2(1 \%)$ & $0(0 \%)$ \\
\hline Bowls & $2(1 \%)$ & $0(0 \%)$ \\
\hline
\end{tabular}

This article is protected by copyright. All rights reserved. 
Table 4: Barriers to, and Facilitators of Physical Activity

Table 4a) Barriers to Physical Activity

\begin{tabular}{|l|l|l|}
\hline ype & $\begin{array}{l}\text { Hospital } \\
\mathbf{N = 1 3 7}\end{array}$ & $\begin{array}{l}\text { Community/'Mixed' } \\
\mathbf{N}=61\end{array}$ \\
\hline In general ..... & & \\
\hline Tiredness/fatigue & $123(54 \%)$ & $52(64 \%)$ \\
\hline Childcare/family responsibilities & $65(29 \%)$ & $18(22 \%)$ \\
\hline Lack of motivation & $44(19 \%)$ & $18(22 \%)$ \\
\hline Stress & $24(11 \%)$ & $15(18 \%)$ \\
\hline Lack of habit & $5(2 \%)$ & $3(4 \%)$ \\
\hline Workplace specific.... & & \\
\hline Unpredictable breaks & $112(60 \%)$ & $32(57 \%)$ \\
\hline Shift patterns & $108(48 \%)$ & $27(33 \%)^{*}$ \\
\hline Long shifts & $97(43 \%)$ & $24(29 \%)^{*}$ \\
\hline In the same place for a long period & $53(28 \%)$ & $19(34 \%)$ \\
\hline Job requires me to sit & $43(23 \%)$ & $17(30 \%)$ \\
\hline Eat lunch at my desk & $24(13 \%)$ & $16(29 \%)^{* *}$ \\
\hline
\end{tabular}

Table 4b) Facilitators of Physical Activity

\begin{tabular}{|l|l|l|}
\hline Type & $\begin{array}{l}\text { Hospital } \\
\text { N= 137 }\end{array}$ & $\begin{array}{l}\text { Community/'Mixed' } \\
\text { N=61 }\end{array}$ \\
\hline Cheaper/subsidised access to facilities & $54(39 \%)$ & $20(33 \%)$ \\
\hline Workplace physical activity challenges & $49(36 \%)$ & $29(48 \%)$ \\
\hline Protected breaks/meal times & $43(31 \%)$ & $23(38 \%)$ \\
\hline Structured exercise classes at work & $39(29 \%)$ & $30(49 \%)^{* *}$ \\
\hline Facilities for showering /changing & $22(16 \%)$ & $15(25 \%)$ \\
\hline Knowing what is available locally & $23(17 \%)$ & $11(18 \%)$ \\
\hline Activities that would include my family & $17(12 \%)$ & $8(13 \%)$ \\
\hline Breaks with colleagues & $14(10 \%)$ & $12(20 \%)$ \\
\hline
\end{tabular}

$p<.05 ;^{*} p<.01^{* *}$

This article is protected by copyright. All rights reserved. 